\title{
CARAMUJO AFRICANO: APENAS UMA ESPÉCIE INTRODUZIDA OU UM PROBLEMA DE SAUDE PÚBLICA?
}

\author{
Marcelo Nocelle ALMEIDA \\ Universidade Federal Fluminense, Instituto do Noroeste Fluminense de Educação Superior, Santo Antônio de Pádua, \\ RJ, Brasil. \\ *Autor para correspondência: mnocelle@ vm.uff.br \\ http://dx.doi.org/10.18571/acbm.112
}

\section{RESUMO}

Esta revisão objetiva alertar e informar a população em geral e os profissionais de saúde quanto à atuação do caramujo africano [Achatina fulica (Bowdich, 1822)], como hospedeiro intermediário, na transmissão de nematoides de interesse veterinário e humano. Também demonstra o papel das conchas como criadouros para mosquitos vetores de diversas viroses, algumas inclusive com alta incidência no norte e noroeste fluminense.

Palavras-chave: Achatina fulica; Controle de Caramujos; Zoonoses.

\begin{abstract}
This review aims at alerting and informing the general population and health professionals about the acting of the African snail [Achatina fulica (Bowdich, 1822)] as an intermediate host in the transmission of nematodes of veterinary and human interest. It also demonstrates the role of shells as breeding sites for mosquito vectors of various viruses, some of which are also highly prevalent in the north and northwest of the state of Rio de Janeiro.
\end{abstract}

Keywords: Achatina fulica; Control of Snails; Zoonoses.

\section{Introdução}

O caramujo africano [Achatina fulica (Bowdich, 1822)] é um molusco terrestre originário da região leste da África. O primeiro relato de estragos causados por esta espécie em plantações foi registrado em 1812, na ilha de Madagascar, onde foi introduzida por um governador francês. A partir de Madagascar, expandiu-se pelo mundo: Ilhas Mascarenhas, Maldivas, Índia, Sri Lanka, Malásia, Melanésia, Filipinas, Hong Kong, Micronésia, Polinésia e Havaí (MEAD, 1979; THIENGO et al., 2007). Sua entrada no continente americano ocorreu junto com material de guerra norte-americano repatriado das ilhas do Pacífico (BARBOSA e SALGADO, 2001). Nos Estados Unidos provocou grandes estragos, principalmente na Califórnia e na Flórida (TELES e FONTES, 2000).

No Brasil, foi introduzido em 1988 no estado do Paraná (REVISTA GLOBO RURAL, 1992). Em outubro de 1990, na VI Feira Agropecuária de Curitiba, foram comercializados 100 lotes dessa espécie, que naquela oportunidade, foi denominada de escargot chinês (REINERT, 1990), o que não corresponde à verdade, uma vez que, os escargots verdadeiros são duas espécies de origem europeia, Helix aspersa (O.F. Müller, 1774) e Helix pomatia Linnaeus, 1758.

A partir desse evento foi feita uma ampla divulgação por meio de diversos veículos de comunicação e surgiram apostilas e fitas em VHS de cursos ensinando sua criação e comercialização. A resistência ao calor, alta taxa reprodutiva, crescimento e ganho de peso mais rápido que os escargots verdadeiros foram às características biológicas utilizadas para reforçar sua entrada no mercado nacional. Uma empresa sediada em Campo Limpo Paulista vendia contratos 
que fornecia matrizes, ração, orientação de técnicos especializados e ainda o compromisso de compra de toda a produção (JUNQUEIRA, 2001).

Porém, o produto não foi bem aceito no mercado e a empresa faliu. Os insucessos dos investimentos fizeram os criadores abandonarem ou soltarem suas criações no ambiente. Outra forma de dispersão da espécie foi os pesque-pague, onde os caramujos foram utilizados como isca (JUNQUEIRA, 2001). Devido ao hábito alimentar generalista e ao seu alto potencial reprodutivo colonizou diversos ambientes, sendo considerada uma das cem piores pragas do mundo (ESTON et al., 2006).

\section{Distribuição do caramujo africano no norte-noroeste fluminense}

A mesorregião norte fluminense é constituída por nove municípios: Campos dos Goytacazes, Carapebus, Cardoso Moreira, Conceição de Macabu, Macaé, Quissamã, São Fidélis, São Francisco de Itabapoana e São João da Barra.

A mesorregião noroeste fluminense é composta por 13 municípios: Aperibé, Bom Jesus de Itabapoana, Cambuci, Italva, Itaocara, Itaperuna, Laje do Muriaé, Miracema, Natividade, Porciúncula, Santo Antônio de Pádua, São José de Ubá e Varre-Sai.

Em 2010, segundo Zanol et al. (2010), apenas nove, entre os 92 municípios do estado do Rio de Janeiro, ainda não registravam a presença do caramujo africano: Areal, Bom Jardim, Cambuci, Duas Barras, Engenheiro Paulo de Frontin, Macuco, Rio das Flores, Sumidouro e Varre-Sai. Entre os municípios livres do caramujo africano naquela data, estava Cambuci e Varre-Sai, ambos da mesorregião noroeste fluminense. Contudo, em Varre-Sai sua presença já foi observada recentemente (ABIB, 2012). Em Cambuci provavelmente o molusco também já está presente, porém, ainda não foi publicado nenhum material acerca de sua presença naquele município.

\section{Problemas em decorrência da introdução do caramujo africano}

A introdução dessa espécie trás três problemas: (1) ameaça de extinção para as espécies de caramujos nativas, (2) criadouros para mosquitos do gênero Aedes sp. Meigen, 1818 e (3) hospedeiro intermediário de parasitos humanos e de animais domésticos. Não será tratada nesse texto a questão da competição com as espécies nativas de caramujos, pois, objetiva-se nesse trabalho relacionar a presença do caramujo africano com a saúde pública.

\section{Criadouros para mosquitos do Gênero Aedes Meigen, 1818}

Os mosquitos do Gênero Aedes Meigen, 1818 são vetores de viroses como dengue, febre amarela, febre Chikungunya e a febre Zika. As duas principais espécies de mosquitos responsáveis pela transmissão dessas doenças são Aedes aegypti Linnaeus, 1762 e Aedes albopictus Skuse, 1894. Ambas são espécies introduzidas no Brasil, sendo a primeira de origem africana e a segunda de origem asiática. O A. aegypti foi introduzido no Brasil durante o período do tráfico de escravos da África, e o A. albopictus entrou no Brasil na década de 1980 por meio de navios que faziam o transporte de ferro para o Japão (CONSOLI e OLIVEIRA, 1998).

A espécie $A$. aegypti transmite comprovadamente as quatro viroses citadas anteriormente, enquanto que A. albopictus é vetor natural do dengue em áreas rurais, suburbanas e urbanas na Ásia. No Brasil, ainda não foi observada a transmissão dessa virose por esse mosquito. Contudo, larvas já foram encontradas infectadas por Dengue tipo I e foi comprovada experimentalmente a suscetibilidade e a infecção de adultos pelos quatro sorotipos do vírus do dengue (CONSOLI e OLIVEIRA, 1998).

O ciclo de vida desses mosquitos inclui quatro fases: ovo, larva, pupa e adulto. Os ovos são depositados nas paredes de recipientes contendo água parada, com fundo e/ou paredes escuras. Os 


\section{Biomedica Brasiliensia}

principais criadouros para essas espécies de mosquito são artificiais como reservatórios para armazenar água para uso doméstico, pneus, pratos de vasos, caixas d'água, toneis, latões, piscinas e aquários abandonados (LIMA-CAMARA et al., 2016). Os criadouros naturais são flores ornamentais (principalmente bromélias) (FORATTINI e MARQUES, 2000) e cavidades de árvores (LIMA-CAMARA et al., 2016).

A concha nos moluscos adultos, em geral, é uma espiral alongada e cônica constituída por carbonato de cálcio. Após a morte do animal, a parte mole é rapidamente decomposta por bactérias, fungos e insetos. Contudo, a concha leva muito tempo para ser completamente degradada e pode permanecer no ambiente por décadas.

Quando os caramujos africanos morrem e a parte mole do seu corpo é decomposta, normalmente a concha fica com a abertura voltada para cima, o que poderá acumular água de chuva e se transformar em um criadouro para as duas espécies de mosquitos. A primeira citação da utilização de concha vazia do caramujo africano como criadouro para A. aegypti foi feita por Trpis (1973) na Tanzânia. Segundo aquela pesquisa, as conchas vazias quando se encontram em locais sombreados pela vegetação servem como locais para a reprodução de diversas espécies de mosquitos. Os detritos orgânicos que elas contêm são utilizados como recursos alimentares para as larvas.

No Brasil, conchas de caramujos africanos contendo larvas de Aedes sp. foram encontradas em Campinas/SP em 2001 (GOMES, 2016) e em Santo Antônio de Pádua/RJ, onde foi observada uma concha contendo água da chuva sem larvas (Figura 1A) e outra com larvas de espécie não identificada (Figura 1B).

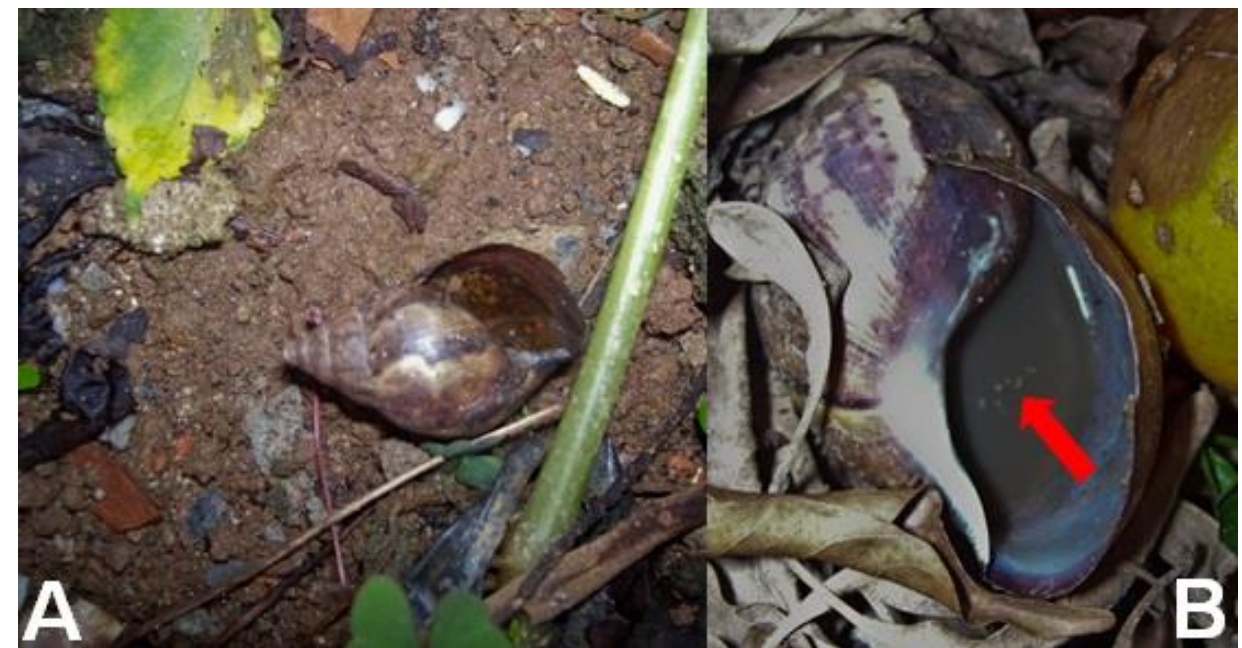

Figura 1: Conchas de caramujo africano acumulando água da chuva em Santo Antônio de Pádua/RJ: (A) sem a presença de larvas; (B) com a presença de larvas de mosquito (evidenciada pela seta vermelha). A espécie das larvas não foi identificada.

Dengue é uma doença preocupante para as mesorregiões norte/noroeste fluminense. Os dados acerca dos casos notificados em 2015 estão demonstrados na Tabela 1. Dentre esses números foram registrados ainda dois casos de óbitos, um em Campos dos Goytacazes e um em Miracema. Em 2015, na mesorregião norte fluminense, os maiores números de casos registrados foram nos municípios de Campos dos Goytacazes (3.415) e Macaé (760). Na mesorregião noroeste fluminense, os municípios com os maiores números de casos foram Itaperuna (2.039), Santo Antônio de Pádua (590), Bom Jesus de Itabapoana (530) e Natividade (479). Não houve casos confirmados de febre Chikungunya e febre Zika em ambas as mesorregiões em 2015 (BOLETIM EPIDEMIOLÓGICO 012/2015). 
Tabela 1: Casos de dengue notificados nas mesorregiões norte e noroeste fluminense em 2015 e até agosto de 2016.

\begin{tabular}{lcccc}
\hline \multicolumn{1}{c}{ Índices } & \multicolumn{2}{c}{ Norte } & \multicolumn{2}{c}{ Noroeste } \\
\cline { 2 - 5 } \multicolumn{1}{c}{ Avaliados } & 2015 & Até agosto/2016 & 2015 & Até agosto/2016 \\
\hline № de casos notificados & 4.804 & 2.733 & 4.364 & 7.715 \\
Percentual & 7,5 & 3,7 & 6,8 & 10,3 \\
Incidência/100 mil habitantes & 544,3 & 306,4 & $1.300,0$ & $2.292,2$ \\
\hline
\end{tabular}

Fonte: Boletim Epidemiológico 012/2015 - 006/2016.

Dentre todas as mesorregiões do estado em 2016, a mesorregião Noroeste fluminense foi a segunda maior em número de casos confirmados de dengue (Tabela 1), ficando atrás somente da mesorregião Serrana com 10.246 casos. Em 2016, foram notificados no estado do Rio de Janeiro, 13.057 casos prováveis de Chikungunya. No norte e noroeste fluminense houve nove e 54 casos, respectivamente. Os casos prováveis de Zika no estado somaram 62.939 casos. Entre esses, 628 e 471 casos foram no norte e noroeste fluminense, respectivamente (BOLETIM EPIDEMIOLÓGICO 006/2016).

As campanhas de combate ao dengue, Chikungunya e Zika se concentram principalmente nos criadouros artificiais, no entanto, bastam poucos criadouros naturais para que a espécie continue seu ciclo na região. Como os caramujos africanos, assim como o A. aegypti, apresentam distribuição prioritariamente sinantrópica, as conchas vazias adquirem uma importância epidemiológica muito grande, uma vez que, em geral, os animais mortos, e, consequentemente suas conchas vazias se encontram em meio à vegetação ornamental, e passa despercebida pela maioria da população, o que bastará para manter o ciclo de vida peridomiciliar do mosquito.

\section{Hospedeiro intermediário de parasitos humanos e de animais domésticos}

O caramujo africano é hospedeiro em potencial de diversos helmintos que parasitam humanos e animais domésticos.

\subsection{Aelurostrongylus abstrusus (Railliet, 1898)}

Esse nematódeo parasita o sistema respiratório (ductos alveolares, bronquíolos terminais e pequenos ramos das artérias pulmonares) de felídeos causando aelurostrongilose ou estrongiloidose cárdio-pulmonar. Gatos infectados eliminam larvas de primeiro estádio nas fezes, as quais são ingeridas ou penetram nos hospedeiros intermediários, os gastrópodes terrestres. Anfíbios, répteis, pássaros e pequenos mamíferos podem ser hospedeiros paratênicos. Gatos se infectam quando ingerem o hospedeiro intermediário ou o paratênico infectados pelas larvas de terceiro estádio (L3) (ZANOL et al., 2010; ANDRADE-PORTO et al., 2012).

Caramujos africanos infectados por A. abstrusus foram registrados no Espírito Santo, Goiás, Mato Grosso, Minas Gerais, Rio de Janeiro, São Paulo e Sergipe THIENGO et al., 2008; OHLWEILER et al., 2010). Segundo Thiengo et al. (2008) esse parasito é o mais frequentemente encontrado em A. fulica. Essa informação é corroborada pelos estudos de Oliveira et al. (2010) em Goiás e Andrade-Porto et al. (2012) em Manaus/AM, onde foram encontradas prevalências de 35 e $40 \%$, respectivamente, em caramujos africanos.

\subsection{Angiostrongylus costaricensis (Morera e Céspedes, 1971)}

Os principais hospedeiros desse nematoide são roedores silvestres, contudo, humanos podem ser hospedeiros acidentais. Em humanos causa a angiostrongilíase abdominal. As principais patologias provocadas por esse parasito em humanos são danos no endotélio de artérias mesentéricas superiores dos ramos íleo-ceco-cólicos, o que poderá provocar trombose e necrose 
da região irrigada pelo vaso. Também podem ser observadas áreas inflamadas devido à ação de ovos, larvas, produtos de excreção e secreção do parasito (MORERA, 1988). Os sintomas mais comuns são febre, anorexia, náuseas, vômitos, dores abdominais, eosinofilia sanguínea, e, raramente, uma massa palpável no quadrante inferior direito, semelhante a um quadro apendicular agudo (MEDEIROS et al., 2009). Como não há eliminação de ovos nas fezes humanas e o quadro clínico não é específico, o diagnóstico clínico torna-se muito difícil. A maioria dos casos diagnosticados foi por meio de exames patológicos de peças cirúrgicas. Tentaram-se testes imunodiagnósticos, mas esses demonstraram dificuldades com reações cruzadas não permitindo uma conclusão segura. Silva et al. (2003) realizaram com sucesso a identificação desse parasito utilizando a técnica de PCR. Segundo os autores, o teste de diagnóstico molecular tem potencial para uso clínico e estudos epidemiológicos.

O clico biológico desse nematoide se inicia pela eliminação de larvas $\left(\mathrm{L}_{1}\right)$ nas fezes dos hospedeiros definitivos (roedores silvestres). Os moluscos ingerem estas larvas junto com o alimento, ou ainda pode ocorrer penetração ativa através da epiderme do molusco. Dentro do molusco a larva sofre duas mudas chegando ao estádio de $\mathrm{L}_{3}$. Essa larva abandona o molusco junto com o muco secretado pela glândula pedial. Os hospedeiros definitivos se infectam ingerindo alimento contaminado pelo muco dos moluscos, ou ainda por ingestão do próprio molusco. Os principais moluscos hospedeiros intermediários são as lesmas da Família Veronicellidae. Entretanto, tem-se observado outras espécies de gastrópodes terrestres e aquáticos atuando como hospedeiros desse parasito.

Carvalho et al. (2003) infectaram 37 indivíduos de $A$. fulica com larvas $\left(\mathrm{L}_{1}\right)$ de $A$. costaricensis, e, desses, 12 indivíduos eliminaram larvas infectantes $\left(\mathrm{L}_{3}\right)$. Todavia, os autores afirmaram que embora o caramujo africano seja suscetível a infecção por larvas de $A$. costaricensis, requer um alto nível de exposição larval para a infecção. Posteriormente, Neuhauss et al. (2007) infectaram experimentalmente caramujos africanos, selvagens e criados em cativeiro, resultando em baixa carga parasitária. Os mesmos autores examinaram 244 indivíduos oriundos de Florianópolis/SC, encontrando apenas um indivíduo infectado com larvas de Metastrongylidae, o que demonstra que essa espécie de molusco apresenta até o momento um baixo risco para a transmissão desse nematoide.

\subsection{Angiostrongylus cantonensis (Chen, 1935)}

Esse nematoide é comum em países do sudeste asiático e ilhas do Pacífico. Seu primeiro registro no continente americano foi em Cuba, e, posteriormente na Jamaica, Estados Unidos e Equador (MORASSUTTI et al., 2014). De acordo com Diaz (2008), a introdução desse parasito no continente americano ocorreu em containers transportados por navios durante o período pósguerra. No Brasil, foi detectado pela primeira vez no município de Cariacica/ES em 2007 (CALDEIRA et al., 2007).

Os hospedeiros definitivos desse parasito são as ratazanas ou ratos castanhos (Rattus norvegicus Berkenhout, 1769), cuja origem é o leste da Ásia. Recentemente, Moreira et al. (2013) encontraram também o rato preto (Rattus rattus Linnaeus, 1758) infectado com larvas de A. cantonensis em Belém/PA. Esse rato é originário do sudeste asiático. Nesses hospedeiros, os nematoides adultos vivem nas artérias pulmonares, de eliminam larvas de primeiro estádio $\left(\mathrm{L}_{1}\right)$. Essas larvas migram para a árvore brônquica, traqueia até serem engolidas e eliminadas juntamente com as fezes. No ambiente, as larvas penetram no tegumento ou são ingeridas pelos moluscos hospedeiros intermediários. Após duas mudas, o estádio larval infectante é eliminado por meio de secreções mucosas dos moluscos, e podem ser ingeridas pelos humanos junto com moluscos mal cozidos ou alimentos ingeridos crus. As larvas perfuram a parede do intestino a caem na corrente sanguínea, e, normalmente alojam-se nas meninges do sistema nervoso central, onde sofrem mais duas mudas e morrem. Para maiores detalhes acerca da fisiopatologia veja Morassutti et al. (2014). 


\section{Biomedica Brasiliensia}

ISSN: 2236-0867

Caramujos africanos parasitados por A. cantonensis tem sido reportado no Espírito Santo, Pará, Paraná, Pernambuco, Rio Grande Sul, Rio de Janeiro, Santa Catarina e São Paulo (LIMA et al., 2009; MALDONADO JÚNIOR et al., 2010, THIENGO et al., 2010; MOREIRA et al., 2013; OLIVEIRA et al., 2015). Carvalho et al. (2012) conduziram um amplo estudo em áreas portuárias no Brasil procurando registrar a presença de A. cantonensis em moluscos terrestres. Foram investigados 30 portos, dos quais $11(36,6 \%)$ continham moluscos infectados por larvas de $A$. cantonensis. O caramujo africano encontrava-se infectado por larvas desse nematoide nos portos de Ilhéus/BA, Angra dos Reis/RJ, Paranaguá/PR e Navegantes/SC. Oliveira et al. (2015) avaliaram o papel de A. fulica na transmissão de A. cantonensis no distrito de Trindade, município de São Gonçalo/RJ. A prevalência encontrada foi superior a $50 \%$.

\section{Profilaxia}

Para evitar que as conchas de caramujos africanos sirvam de criadouros para o mosquito vetor das viroses dengue, febre amarela, febre Chikungunya e a febre Zika, as conchas devem ser quebradas e enterradas, como será visto mais adiante. As demais parasitoses são evitadas lavando bem as frutas, verduras e legumes, principalmente aqueles ingeridos crus, e, jamais consumir a carne do caramujo africano. A eliminação de qualquer tipo de objeto que possa ser utilizado para abrigo de ratos, bem como manter bem protegido todos os itens utilizados como alimentos pelos ratos.

\section{Medidas de controle de Achatina fulica (Bowdich, 1822)}

A principal substância química para controle de moluscos terrestres é à base de metaldeído. Sua ação provoca uma excessiva produção de muco e causa a morte dos gastrópodes por desidratação. A eficiência dessa substância é questionada por várias razões: (a) necessidade de sincronizar sua aplicação com períodos em que os caramujos estão mais ativos, (b) tem efeito tóxico residual em condições de elevada umidade e também (c) é tóxica para mamíferos e organismos aquáticos (HENDERSON e TRIEBSKORN, 2002).

A correta identificação do caramujo africano é a primeira etapa para iniciar os procedimentos de controle. A identificação deve ser feita por profissionais capacitados para evitar que algumas espécies nativas ameaçadas de extinção possam ser confundidas com o caramujo africano e eliminadas incorretamente.

O método mais eficiente de controle das populações de caramujos africanos é a catação manual dos moluscos e ovos. Todos os procedimentos de manipulação dos animais devem ser feito com as mãos protegidas por luvas plásticas ou sacolas plásticas de supermercados (Figura2).

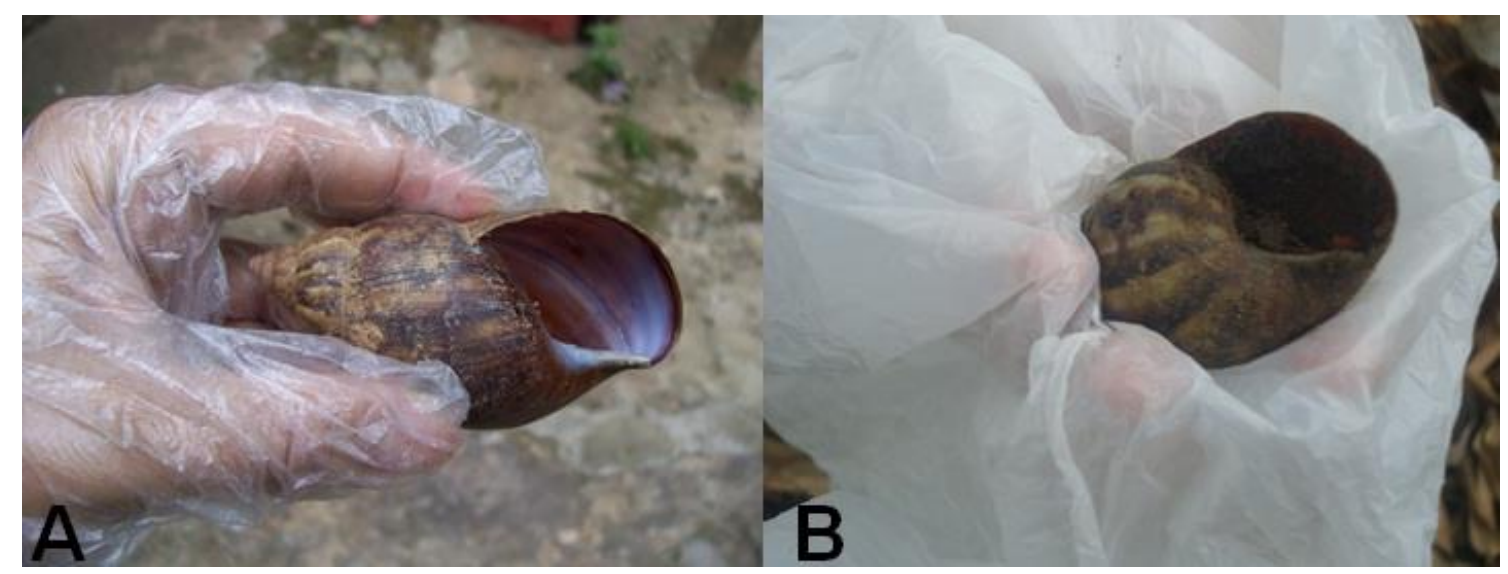

Figura 2: Manuseio de concha de caramujo africano com as mãos protegidas por luvas plásticas (A) e por sacolas de supermercado (B). 
As coletas devem ser feitas no início da manhã, final da tarde e a noite. A vistoria do local deve ser feita embaixo de serapilheira, troncos caídos, rochas e entre raízes. O solo é o principal sítio de repouso dessa espécie, seguido pela vegetação e por último em superfícies antrópicas, tais como muros, paredes e cercas de bambu. Os ovos são depositados em ninhos cavados no solo, onde se encontra a maioria dos ovos. Os ninhos podem ser identificados pela presença de alguns ovos na superfície do solo (BRASIL: VIGILÂNCIA E CONTROLE DE MOLUSCOS DE IMPORTÂNCIA EPIDEMIOLÓGICA, 2007; ALMEIDA, 2013).

Após a coleta, os animais devem ser colocados em um tambor ou lata, onde as conchas devem ser quebradas e posteriormente podem ser incineradas. É comum a utilização de sal diretamente nos animais, e, consequentemente no solo (Figura 3A). Entretanto, esse procedimento não deve ser realizado, uma vez que irá alterar as características químicas do solo. Em qualquer método utilizado é necessário quebrar as conchas, e posteriormente enterrá-las em locais distantes de cisternas, poços artesianos e lenções freáticos. Na Figura 3B podem ser observadas algumas conchas queimadas, o que é suficiente para matar os animais, mas não o bastante para destruir as conchas. Ainda na Figura 3B, observam-se três conchas com as aberturas voltadas para cima com restos de matéria orgânica em decomposição, o que nessas condições poderão acumular água da chuva e fornecer alimento para as larvas, tornando-se um criadouro para os mosquitos.

A catação deve ser feita ao longo do ano ou sempre que se notar a presença dos moluscos, inclusive no inverno, pois são ativos e se reproduzem nessa época do ano (ALMEIDA, 2013). Além disso, evitar o acúmulo de telhas, tijolos, tábuas e a manutenção de jardins ou o cultivo de plantas ornamentais muito adensadas, o que irá proporcionar abrigos para os moluscos.

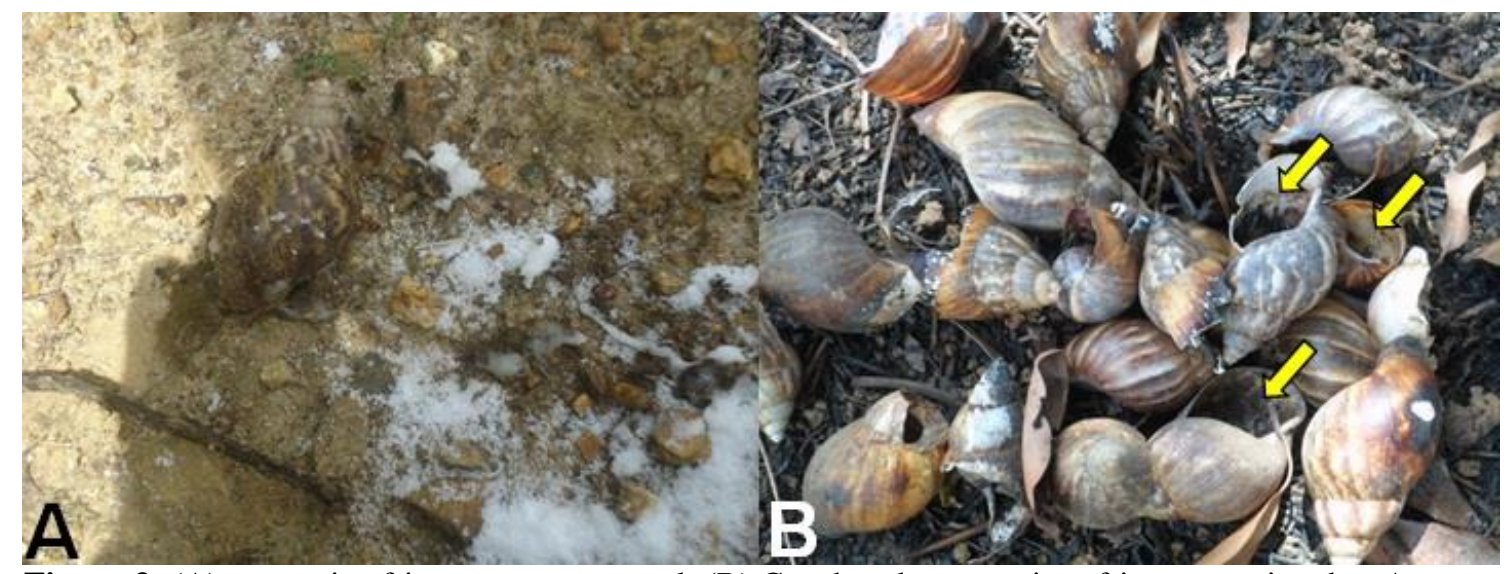

Figura 3: (A) caramujo africano morto com sal; (B) Conchas de caramujos africanos queimadas. As setas indicam três conchas intactas e que podem se tornar criadouros para os mosquitos vetores de diversas viroses.

\section{Considerações Finais}

O aumento da urbanização e da pobreza são fatores que elevam o risco da disseminação de doenças zoonóticas (HIMSWORTH et al., 2013), principalmente, para aquelas cujos vetores e hospedeiros (invertebrados e vertebrados) possuem hábitos sinantrópicos. A aglomeração humana aumenta a disponibilidade de habitats e alimentos para os ratos (OLIVEIRA e BONVICINO, 2006) e a oferta de recipientes propícios para se tornarem criadouros de mosquitos vetores de viroses (SILVA et al., 2006).

A presença dos caramujos africanos [Achatina fulica (Bowdich, 1822)] em praticamente todos os municípios das mesorregiões norte e noroeste fluminense potencializam essas questões, uma vez que, sua concha pode servir como criadouro para os mosquitos vetores e são hospedeiros intermediários de parasitoses de interesse médico veterinário e de saúde pública. 
Dessa forma, diversos setores do poder público (profissionais de saúde humana e veterinária), pesquisadores da área de zoologia e a população em geral das mesorregiões norte e noroeste fluminense devem ficar em alerta quanto a presença dos caramujos africanos e as doenças potencialmente por eles veiculadas.

\section{Referências}

ABIB, C. Varre-Sai participa do I Encontro de Saúde Ambiental do Noroeste Fluminense. Jornal Dois Estados, Miracema, 15 jun. 2012. Disponível em: <www.doisestados.com.br〉. Acesso em: 09 ago. 2016.

ALMEIDA, M.N. Abundância, sazonalidade, reprodução e crescimento da concha de uma população de Achatina fulica [Bowdich, 1822] [Mollusca, Achatinidae] em ambiente urbano. Arquivos de Ciências Veterinárias e Zoologia da UNIPAR, v. 16: p. 51-60. 2013.

ANDRADE-PORTO, S.M.; SOUZA, K.C.P.; CARDENAS, M.Q.; ROQUE, R.A.; PIMPÃO, D.M.; ARAÚJO, C.S.; MALTA, J.C.O. Occurrence of Aelurostrongylus abstrusus (Railliet, 1898) larvae (Nematoda: Metastrongylidae) infecting Achatina (Lissachatina) fulica Bowdich, 1822 (Mollusca: Gastropoda) in the Amazon region. Acta Amazonica, v. 42, n. 2, p. 245-250. 2012.

BARBOSA, A.F.; SALGADO, N.C. Cultivo de caracóis destrói hortas e plantas ornamentais: quando o escargot vira praga. Ciência Hoje, v. 30, n. 175, p. 51-53. 2001.

BRASIL. MINISTÉRIO DA SAÚDE. Secretaria de Vigilância em Saúde. Departamento de Vigilância Epidemiológica. Vigilância e controle de moluscos de importância epidemiológica: diretrizes técnicas: Programa de Vigilância e Controle da Esquistossomose (PCE)/Ministério da Saúde, Secretaria de Vigilância em Saúde, Departamento de Vigilância Epidemiológica. - 2. ed. - Brasília: Editora do Ministério da Saúde, 2007. 178 p.: il. - (Série A. Normas e Manuais Técnicos).

CALDEIRA, R.L.; MENDONÇA, C.L.G.F.; GOVEIA, C.O.; LENZI, H.L.; GRAEFFTEIXEIRA, C.; LIMA, W.S.; MOTA, E.M.; PECORA, I.L.; MEDEIROS, A.M.Z.; CARVALHO, O.S. First record of molluscs naturally infected with Angiostrongylus cantonensis (Chen, 1935) (Nematoda: Metastrongylidae) in Brazil. Mem. Inst. Oswaldo Cruz, v. 102, n. 7, p. 887-889. 2007.

CARVALHO, O.S.; TELES, H.M.S.; MOTA, E.M.; MENDONÇA, C.L.G.F.; LENZI, H.L. Potentiality of Achatina fulica Bowdich, 1822 (Mollusca: Gastropoda) as intermediate host of the Angiostrongylus costaricensis Morera \& Céspedes 1971. Revista da Sociedade Brasileira de Medicina Tropical, v. 36, n. 6, p. 743-745. 2003.

CARVALHO, O.S.; SCHOLTE, R.G.C.; MENDONÇA, C.L.F.; PASSOS, L.K.J.; CALDEIRA, R.L. Angiostrongylus cantonensis (Nematode: Metastrongyloidea) in molluscs from harbour areas in Brazil. Mem. Inst. Oswaldo Cruz, v. 107, n. 6, p. 740-746. 2012.

CONSOLI, R.A.G.B.; OLIVEIRA, R.L. Principais mosquitos de importância sanitária no Brasil. Rio de Janeiro: Editora Fiocruz. 1998.

DIAZ, J.H. Helminth eosinophilic meningitis: emerging zoonotic diseases in the South. The Journal of the Louisiana State Medical Society, v. 160, p. 333-342. 2008. 
ESTON, M.R.; MENEZES, G.V.; ANTUNES, A.Z.; SANTOS, A.S.R..; SANTOS, A.M.R. Espécie invasora em unidade de conservação: Achatina fulica (Bowdich, 1822) no Parque Estadual Carlos Botelho, Sete Barras, SP, Brasil. Rev. Inst. Flor. São Paulo, v. 18, p. 173-179. 2006.

FORATTINI, O.P.; MARQUES, G.R.A.M. Nota sobre o encontro de Aedes aegypti em Bromélias. Rev. Saúde Pública, v. 34, n. 5, p. 543-544. 2000.

GOMES, M. Biologia Virtual: Disponível <http://sitebiologico.blogspot.com.br/search/label/Zoologia>. Acesso em: 17 ago. 2016.

HENDERSON, I.; TRIEBSKORN, R. Chemical Control of Terrestrial Gastropods. In: BARKER, G.M. (Ed.). Molluses as Crop Pests. Trowbridge: CAB International Publishing, 2002. p. 1-31.

HIMSWORTH, C.G.; PARSONS, K.L.; JARDINE, C.; PATRICK, D.M. Rats, Cities, People, and Pathogens: A Systematic Review and Narrative Synthesis of Literature Regarding the Ecology of Rat-Associated Zoonoses in Urban Centers. Vector-Borne and Zoonotic Diseases, v. 13, n. 6, p. 349-359. 2013.

JUNQUEIRA, A.C. Em busca da legalidade. O Estado de São Paulo, São Paulo, 10 out. 2001.

LIMA, A.R.M.C.; MESQUITA, S.D.; SANTOS, S.S.; AQUINO, E.R.P.; ROSA, L.R.S.; DUARTE, F.S.; TEIXEIRA, A.O.; COSTA, Z.R.S.; FERREIRA, M.L.B. Alicata disease: neuroinfestation by Angiostrongylus cantonensis in Recife, Pernambuco, Brazil. Arquivos de Neuro-Psiquiatria, v. 67, n. 4, p. 1093-1096. 2009.

LIMA-CAMARA, T.N.; URBINATTI, P.R.; CHIARAVALLOTI-NETO, F. Encontro de Aedes aegypti em criadouro natural de área urbana, São Paulo, SP, Brasil. Rev Saúde Pública, v. 50, n. 3, p. 1-4. 2016.

MALDONADO JÚNIOR, A.; SIMÕES, R.O.; OLIVEIRA, A.P.M.; MOTTA, E.M.; FERNANDEZ, M.A.; PEREIRA, Z.M.; MONTEIRO, S.S.; TORRES, E.J.L.; THIENGO, S.C. First report of Angiostrongylus cantonensis (Nematoda: Metastrongylidae) in Achatina fulica (Mollusca: Gastropoda) from Southeast and South Brazil. Mem. Inst. Oswaldo Cruz, v. 105, n. 7, p. 938-941. 2010.

MEAD, A.R. Economic malacology with particular reference to Achatina fulica. In: FRETTER, V.; PEAKE, P. (Ed.). Pulmonates. London: Academic Press, 1979. p. 1-150.

MEDEIROS, F.; CREPALDI, N.; TOGNOLI, L.; NEVES, M.F. Angiostrongylus costaricencis. Revista Científica Eletrônica de Medicina Veterinária, v. 7, n. 12, p. 1-6. 2009.

MORASSUTTI, A.L.; THIENGO, S.C.; FERNANDEZ, M.; SAWANYAWISUTH, K.; GRAEFF-TEIXEIRA, C. Eosinophilic meningitis caused by Angiostrongylus cantonensis: an emergent disease in Brazil. Mem. Inst. Oswaldo Cruz, v. 109, n. 4, p. 399-407. 2014.

MORERA, P. Angiostrongilíase abdominal: um problema de saúde pública? Revista da Sociedade Brasileira de Medicina Tropical, v. 21, n. 2, p. 81-83. 1988. 


\section{Biomedica Brasiliensia}

ISSN: 2236-0867

MOREIRA, V.L.C.; GIESE, E.G.; MELO, F.T.V.; SIMÕES, R.O.; THIENGO, S.C.; MALDONADO JÚNIOR; A.; SANTOS, J.N. Endemic angiostrongyliasis in the Brazilian Amazon: natural parasitism of Angiostrongylus cantonensis in Rattus rattus and $R$. norvegicus, and sympatric giant african land snails, Achatina fulica. Acta Tropica, v. 125, p. 90-97. 2013.

NEUHAUSS, E.; FITARELLI, M.; ROMANZINI, J.; GRAEFF-TEIXEIRA, C. Low susceptibility of Achatina fulica from Brazil to infection with Angiostrongylus costaricensis and A. cantonensis. Mem. Inst. Oswaldo Cruz, v. 102, n. 1, p. 49-52. 2007.

OHLWEILER, F.P.; GUIMARÃES, M.C.A.; TAKAHASHI, F.Y.; EDUARDO, J.M. Current distribution of Achatina fulica, in the state of São Paulo including records of Aelurostrongylus abstrusus (nematoda) larvae infestation. Rev. Inst. Med. Trop. São Paulo, v. 52, n. 4, p. 211 214. 2010.

OLIVEIRA, J.A.; BONVICINO, C.R. Ordem Rodentia. In: REIS, N.R.; PERACCHI, A.L.; PEDRO, W.A.; LIMA, I.P. (Eds.). Mamíferos do Brasil. Londrina: Nélio R. dos Reis, 2006. p. 347-406.

OLIVEIRA, A.P.M.; TORRES, E.J.L.; MALDONADO JÚNIOR, A.; ARAÚJO, J.L.B.; FERNANDEZ, M.A.; THIENGO, S.C. Achatina fulica como hospedeiro intermediário de nematódeos de interesse médico-veterinário em Goiás, Brasil. Revista de Patologia Tropical, v. 39, n. 3, p. 199-210. 2010.

OLIVEIRA, A.P.M.; GENTILE, R.; MALDONADO JÚNIOR, A.; TORRES, E.J.L.; THIENGO, S.C. Angiostrongylus cantonensis infection in molluscs in the municipality of São Gonçalo, a metropolitan area of Rio de Janeiro, Brazil: role of the invasive species Achatina fulica in parasite transmission dynamics. Mem. Inst. Oswaldo Cruz, v. 110, n. 6, p. 739-744. 2015.

REINERT, H. Escargot chinês está chegando ao mercado. O Estado de S. Paulo, São Paulo, 21 out. 1990.

REVISTA GLOBO RURAL. Escargot - Caracol tropical. São Paulo: Revista Globo Rural, Ano 7, no 75, Janeiro. p. 31-32. 1992.

SECRETARIA DE ESTADO DE SAÚDE DO RIO DE JANEIRO. Gerência de Doenças Transmitidas por Vetores e Zoonoses - GDTVZ. Boletim Epidemiológico 012. Situação Epidemiológica da Dengue/Chikungunya/Zika e Cenário para 2016 no Estado RJ. Dezembro. Semanas Epidemiológicas: 1 a 49. 2015. Disponível em: <http://www.riocontradengue.rj.gov.br/Publico/MostrarArquivo.aspx?C=GKF5fzhJlMM\%3D>. Acesso em: 28 nov. 2016.

SECRETARIA DE ESTADO DE SAÚDE DO RIO DE JANEIRO. Gerência de Doenças Transmitidas por Vetores e Zoonoses - GDTVZ. Boletim Epidemiológico 006. Cenário Epidemiológico: Dengue, Chikungunya e Zika no Estado RJ. Agosto. Semanas Epidemiológicas: 1 a 31. 2016. Disponível em: <http://www.riocomsaude.com.br/ Publico/MostrarArquivo.aspx?C=XFIn0UtahJ8\%3D>. Acesso em: 28 nov. 2016.

SILVA, A.C.A.; GRAEFF-TEIXEIRA, C; ZAHA, A. Diagnosis of abdominal angiostrongyliasis by PCR from sera of patients. Rev. Inst. Med. trop. S. Paulo, v. 45, n. 5, p. 295-297. 2003. 
SILVA, V.C; SCHERER, P.O.; FALCÃO, S.S.; ALENCAR, J.; CUNHA, S.P.; RODRIGUES, I.M.; PINHEIRO, N.L. Diversidade de criadouros e tipos de imóveis frequentados por Aedes albopictus e Aedes aegypti. Rev. Saúde Pública, v. 40, n. 6, p. 1106-1111. 2006.

TELES, H.M.S.; FONTES, L.R. Implicações da introdução e dispersão de Achatina fulica Bowdich, 1822 no Brasil. Boletim do Instituto Adolfo Lutz, v. 12, n. 1, p. 3-5. 2000.

THIENGO, S.C.; FARACO, F.A.; SALGADO, N.C.; COWIE, R.H.; FERNANDEZ, M.A. Rapid spread of an invasive snail in South America: the gigant african snail, Achatina fulica, in Brazil. Biol. Invasions. v. 9, p. 693-702. 2007.

THIENGO, S.C.; FERNANDEZ, M.A.; TORRES, E.J.; COELHO, P.M.; LANFREDI, R.M. First record of a nematode Metastrongyloidea (Aelurostrongylus abstrusus larvae) in Achatina (Lissachatina) fulica (Mollusca, Achatinidae) in Brazil. J. Invertebr. Pathol. v. 98, p.34-39. 2008.

THIENGO, S.C.; MALDONADO, A.; MOTA, E.M.; TORRES, E.J.L.; CALDEIRA, R.; CARVALHO, O.S.; OLIVEIRA, A.P.M.; SIMÕES, R.O.; FERNANDEZ, M.A.; LANFREDI, R.M. The giant african snail Achatina fulica as natural intermediate host of Angiostrongylus cantonensis in Pernambuco, northeast Brazil. Acta Tropica, v. 115, p. 194-199. 2010.

TRPIS, M. Ecological studies on the breeding of Aedes aegypti and other mosquitos in shells of the giant African snail Achatina fulica. Bull. Wld. Hlth. Org., v. 48, p. 447-453. 1973.

ZANOL, J.; FERNANDES, M.A.; OLIVEIRA, A.P.M.; RUSSO, C.A.M.; THIENGO, S.C. The exotic invasive snail Achatina fulica (Stylommatophora, Mollusca) in the State of Rio de Janeiro (Brazil): current status. Biota Neotropical, v. 10, n. 3, p. 447-451, 2010. 